\title{
Developing Critical Thinking Skills Through i-Think Maps: An Action Research
}

\author{
Norma Yaakub ${ }^{1}$, Radzuwan bin Ab. Rashid ${ }^{2}$ \& Noormaizatul Akmar bt Muhammad Nasir ${ }^{3}$ \\ ${ }^{1}$ Language Department, IPG Kampus Sultan Mizan, Terengganu, Malaysia \\ ${ }^{2}$ Faculty of Languages and Communication, Unisza, Terengganu, Malaysia \\ ${ }^{3}$ Academic Service Centre, Kolej Islam Antarabangsa Sultan Ismail Petra, Kelantan, Malaysia \\ Correspondence: Norma bt Yaakub, Language Department, IPG Kampus Sultan Mizan, 22200 Besut, Terengganu, \\ Malaysia.E-mail: norma@ipgmksm.edu.my
}

Received: May 23, 2018 Accepted: June 20,2018 Online Published: November 27, 2018

doi:10.5539/ijel.v8n7p42 URL: https://doi.org/10.5539/ijel.v8n7p42

\begin{abstract}
This paper aims to provide insights into the use of i-Think maps in developing the understanding of critical thinking skill among ESL student teachers. The i-Think map programme was introduced by the Ministry of Education in 2012 which aims to produce innovative learners including those in language learning field. Employing Kemmis and Mac Taggart's (2000) model of action research, eight different types of i-Think maps were introduced to three trainee teachers for four months in order to obtain feedback concerning their learning experience and understanding of critical thinking skill. Throughout the four-month period, the participants were asked to opt for suitable i-Think maps to summarise the content of the lectures delivered in their teaching session. The participants were trainee teachers at a Teacher Training Institute in Malaysia and they were purposively sampled as they had been diagnosed to have problems in applying critical thinking for coaching. Analysis of the data which were generated from document analysis and semi-structured interviews with the student teachers, showed that the participants were interested in using i-Think maps and they perceived the maps as a useful tool in improving their understanding of critical thinking. This paper contributes to the existing literature on critical thinking skills in ELT classroom by highlighting the importance of using i-Think maps as a teaching aid in enhancing the critical thinking ambience among the students.
\end{abstract}

Keywords: critical thinking, i-Think maps, action research, trainee teacher

\section{Introduction}

Providing a new generation with the ability to have excellent thinking skills is very crucial as in tandem with $21^{\text {st }}$ Century education phenomenon. Critical thinking skills involve the processing of information through analysis, synthesis, interpretation, explanation, evaluation, generalization, abstraction, application, comparison and contrast (Santiago, 2011). Malaysian educational values reflected that one of the transformational aspects of the educational curriculum in the Malaysia Education Development Plan (PPPM) 2013 -2025 is to focus on the thinking skills. It is a concept which aims to produce knowledgeable students who are able to think critically and creatively as well as highly competitive up to the international level. It focuses on producing Malaysian generations who are not only knowledgeable but also poses good leadership qualities with strong moral and religious values; the important qualities to qualify them to compete around the globe. Thus, the i-Think map has been entrusted as a visual tool to realize the vision. According to Browne and Freeman (2000) learners are triggered to delve into relevant discussion and evaluation by embedding themselves in active-learning classroom as they involve with the chosen teaching materials. Therefore, i-Think is hoped to be beneficial for the students to transfer the information as suitable teaching materials. Besides, when classroom instruction is given based on argument mapping, it will increase students' critical thinking skill Gelder (2005).

John Dewey is well-known as "father" of the modern critical thinking and he was the one who has started the modern movement of critical thinking. Dewey (1938, p. 9) defines critical thinking as "active, persistent, and careful consideration of any belief or supposed form of knowledge in the light of the grounds that support it and the future conclusions to which it tends". The three main keywords which are active, persistent and careful consideration in gaining information and knowledge from others are very crucial to be adopted by teachers to 
trigger active learning in their classroom (Anh, 2017).

In this vein, Bloom's cognitive domain taxonomy (1956) is popularly cited in teaching higher-order thinking skills. As in defining higher-order thinking skills, the view that will be shared here is, higher-order thinking skills are equivalent with critical thinking (Paul, 1995; Anderson \& Krathwohl, 2001). The six hierarchy levels stated in Bloom's taxonomy are knowledge, comprehension, application, analysis synthesis and evaluation. The first two levels; knowledge and comprehension are considered as low-order thinking skills and involve convergent thinking which means learning happened from ordinary concept determined by text studied or by the teacher. It is proven that analysis, synthesis and evaluation levels are representing critical thinking (Kennedy, Fischer, \& Ellis, 1991). However, Anderson and Krathwohl (2001) have modified and revised Bloom's original framework to adequate outcome-based educational objectives. Some changes include the names of the level from nouns to verbs and reversing the order of the highest two levels (Krathwohl, 2002). Creating is put at the top level of Anderson and Krathwohl revised Bloom's taxonomy as formerly it was synthesis in original taxonomy. This revised version consists of remembering, understanding, analysing, evaluating and creating. Critical thinking is an aspect of thinking activity. It is a form of learning means of generating new knowledge by processing existing knowledge and ideas using the knowledge manipulation tool through various processes such as analysis, understanding and synthesis. Critical thinking skills are most effectively developed and learned when they are taught in conjunction or embedded with content and not in isolation (Warren, Memory, \& Bolinger, 2004). Therefore, in teaching TSL 1044 Language Culture and Society course, the improvement in critical thinking among the students were observed throughout the teaching session. Learners worked together in a group towards a common end when they would be recognizing that they had different perspectives on the same issue. Such difference signaled that critical thinking had taken place as desired. This action research had been carried out in a PISMP Teaching English as Second Language (TESL) classroom investigating how i-Think maps could be used by the students to enhance critical thinking skills and also the understanding of the content taught.

The i-Think map as a Thinking Tool program is to foster and promote the skills of thinking among students to produce an innovative generation. The purpose of introducing i-Think is to produce human capital that has a critical and creative thinking, innovative and competitive in future (Hassan, Rosli, \& Zakaria, 2016). In all aspects of life, learners are dependent upon their ability to think critically, creatively, analytically, independently and compassionately, in order to be successful and to contribute positively to those around them. Thinking Maps can be a tool for acting confidently and constructively in the world (Hyerle \& Yeager, 2007).

The Ministry of Education of Malaysia in collaboration with National Innovation Agency introduce i-Think program. The eight maps in i-Think maps are Circle Map, Bubble Map, Double Bubble Map, Tree Map, Brace Map, Flow Map, Multi-Flow Map and Bridge Map. According to Hyerle and Yeager (2007) who developed i-Think map project, the process of thinking and reasoning becomes a culture when the teachers and students practice the thinking skills and reasoning during teaching and learning. One of the most important aspects of the i-Think maps is the ability for students to display critical thinking skills in order to complete the maps. Savich (2009) states that the focus on critical and independent thinking is an effective way for teachers to maximize the engagement of the students. i-Think maps allow for students to feel more connected to the material, as it encourages them to map out their thought process on paper, which leads to an increase in connections between content and experience. As invented by Hyerle and Yeager (2007) the diagram below describes the feature of i-Think maps and its functions. 


\begin{tabular}{|c|c|c|}
\hline \begin{tabular}{|c|} 
Questions from Toxts, \\
Teachers and Tosts
\end{tabular} & Thinking Processos & $\begin{array}{c}\text { Thinking Maps } \\
\text { as Tools }\end{array}$ \\
\hline $\begin{array}{l}\text { How are you dofining } \\
\text { this thing or idea? What is } \\
\text { the context? What is your } \\
\text { trame of reforenco? }\end{array}$ & $\begin{array}{l}\text { DEFINING IN } \\
\text { CONTEXT }\end{array}$ & $\begin{array}{l}\text { Circlo } \\
\text { Map }\end{array}$ \\
\hline $\begin{array}{l}\text { How are you doscribing } \\
\text { this thing? } \\
\text { which adjoctives } \\
\text { would bost dosoribe } \\
\text { this thing? }\end{array}$ & $\begin{array}{l}\text { DESCRIBING } \\
\text { OUALITIES }\end{array}$ & $\begin{array}{l}\text { Bubble } \\
\text { Map }\end{array}$ \\
\hline $\begin{array}{l}\text { What are the similar } \\
\text { and differont qualitios } \\
\text { of those things? } \\
\text { Which qualitios do you } \\
\text { value most? Why? }\end{array}$ & $\begin{array}{l}\text { COMPARING and } \\
\text { CONTRASTING }\end{array}$ & $\begin{array}{l}\text { Double } \\
\text { Bubble } \\
\text { Map }\end{array}$ \\
\hline $\begin{array}{l}\text { What are the main } \\
\text { idoas. supporting } \\
\text { idoas. and dotails in } \\
\text { this intormation? } \\
\end{array}$ & CLASSIFYING & $\begin{array}{l}\text { Troo } \\
\text { Map }\end{array}$ \\
\hline $\begin{array}{l}\text { What aro tho } \\
\text { componont parts and } \\
\text { subparts of this whole } \\
\text { physical objoct? }\end{array}$ & PART-WHOLE & $\begin{array}{l}\text { Braco } \\
\text { Map }\end{array}$ \\
\hline $\begin{array}{l}\text { What happened? } \\
\text { What is the sequence } \\
\text { of ovents? What are } \\
\text { the substages? }\end{array}$ & SEQUENCING & Map \\
\hline $\begin{array}{l}\text { What are the } \\
\text { causos and offocts } \\
\text { of this ovent? } \\
\text { What might? } \\
\text { happen next? } \\
\end{array}$ & CAUSE and EFFECT & $\begin{array}{l}\text { Multi- } \\
\text { Flow } \\
\text { Map }\end{array}$ \\
\hline $\begin{array}{l}\text { What is tho analogy } \\
\text { boing usood? } \\
\text { What is the guiding } \\
\text { motaphor? }\end{array}$ & $\begin{array}{l}\text { SEEING } \\
\text { ANALOGIES }\end{array}$ & $\begin{array}{l}\text { Bridgo } \\
\text { Map }\end{array}$ \\
\hline
\end{tabular}

Figure 1. i-Think maps

Source: Hyerle \& Yeager (2007).

Considering the importance of i-Think maps as teaching materials and in producing critical thinkers, this study explored research issue, objectives and questions as follows:

\subsection{Research Issue}

Preliminary observations revealed a few factors that have contributed to the problem of applying critical thinking skills in both verbal and written response. The issues are:

1) The exam-oriented practice where students have been taught to 'learn and recall' rather than using their own thoughts.

2) Students have been spoon-fed with information by the teachers since their early schooling instead of findings the information in various other methods.

3) Students showed a tendency of giving back facts when answering questions rather than giving their own ideas.

4) Students faced difficulty to elaborate their own ideas critically.

\subsection{Research Objectives}

The objectives of this action research are:

1) To measure the students' understanding of the use of i-Think maps in promoting critical thinking.

2) To illustrate how i-Think map attracts the students' interest in exploring critical thinking in their academic study.

\subsection{Research Questions}

1) Do i-Think maps improve students' understanding of critical thinking?

2) How can i-Think maps trigger interest among the students in understanding critical thinking skill?

\section{Method}

This action research was carried out through the teaching of an English subject which is Language Culture and Society (TSL 1044) in PPISMP classroom for four months.

The students were asked to listen to the lectures and the given notes on a particular topic. After that, they were asked to discuss and summarize the content learnt. This is in line with Moon (2008) who claims that in order to enhance critical thinking skills, learners shall be exposed to spoken lecture or talk in which evidence is given for a particular stand before they are asked to summarize the content being taught. 


\subsection{Participants}

Three students of PPISMP English Language January 2015 intake were purposively chosen due to their lack of ability to take clear and concise notes of the lesson taught. Apart from that, they appeared to have a poor understanding of critical thinking skill that could be seen from the way they responded to spontaneous questions posed to them in the classroom and also in their written assessment.

\subsection{Description of Research Context}

The participants were taught the correct format for using the eight i-Think maps together with its intended purpose. Then the participants were asked to make notes on the lesson taught as well as the supplied lecture notes by summarizing the lesson contents. They were reminded to use their ability to construct the thinking maps that suit best the context of the contents. Throughout the study, the students were randomly assessed on their ability to process the contents that they learned in the classroom and construct their responses in i-Think maps format. These i-Think maps were then gauged to measure their thinking skills based on Bloom (1956)'s taxonomy and Anderson and Krathwohl (2001) revised version of Bloom's Taxonomy. We classified the given task based on the chosen maps which are appropriate with critical thinking skill levels. As for the revised Version of Bloom's Taxonomy, Anderson and Krathwohl (2001) had modified the framework to adequate outcome-based educational objective which consists of remembering, understanding, applying, analysing, evaluating and creating.

\subsection{Data Generation Process}

In this research, two approaches were used to collect the data namely interview and document analysis.

\subsubsection{Interview}

An individual interview was carried with the participants. During the interview, these questions were asked to the participants:

1) Do you like using i-Think maps?

2) Do you think i-Think maps are interesting?

3) Do you think i-Think maps help you in developing critical thinking skills?

\subsubsection{Document Analysis}

The process began with assigning the students to summarize their learnt-content in their own preferred way and this was done two days before the intervention of i-Think maps. Once briefed on the i-Think maps, again they were asked to summarize the same teaching content using the newly introduced approach. The topic and content of both tasks were maintained throughout the experiment period. In the end, the pre and post products of the i-Think maps produced by the students were analysed.

\subsection{Implementation of Action}

This study employed Kemmis and Mc Taggart (2000) Model which implies the process of planning, acting, observing and reflecting in analyzing the tested concept. Firstly, at the planning stage, any observed changes were initiated prior to the implementation. Next, the consequences of the implementation were observed. Last but not least, reflection was made to unleash the results. However, if the result did not meet the targeted objective, re-planning was to be considered. 


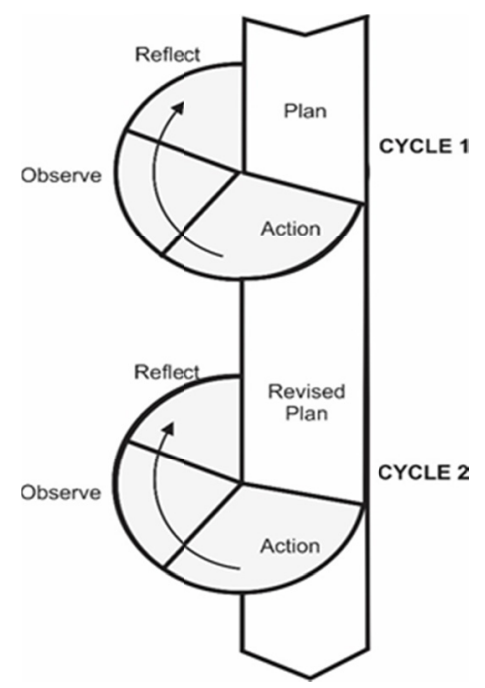

Figure 2. Implementation of action model

Source: Kemmis and Mc Taggart (2000).

\subsubsection{Plan}

First step: Planning

Preliminary observations show that these PPISMP TESL student teachers were lack of effective note-taking skills in both verbal and written information. This scenario indicated that their awareness and understanding of critical thinking skill was still at a very unsatisfactory level. Their works appeared to be effortless as if they did not really put much thought on it especially among the three student teachers. Thus, an intervention for improvement was decided to improve their note-taking and critical thinking skills.

\subsubsection{Action}

\section{Second Step: Implementing the project}

i-Think maps which are well-known for its features and functions to enhance critical thinking skills were taught and used for four months until the participants were able to improve their note-taking and critical thinking skills. They were given various tasks to exercise, practice and understand the various different types of i-Think maps with their respective use.

\subsubsection{Observe}

\section{Third Step: Observing the Project}

Throughout the four months of the implementation period, the trainee teachers were observed to gather some ideas of their understandings of i-Think maps and whether the maps really benefit their studies or vice versa. Other than that, the students' works were collected and analysed through document analysis. This process was done twice; before and after the intervention. These pre and post scores were then compared to see the difference. Last but not least, series of interviews were also conducted on the three student teachers to gain some opinions from the students' perspectives.

\subsubsection{Reflect}

Fourth step: Reflecting and Evaluating

The gathered information throughout the sessions was critically and analytically evaluated. At the end of the sessions, the strengths and weaknesses of the intervention could be seen. This reflection thus can be used for future recommendations.

\section{Results}

The document analysis reveals that the $\mathrm{i}$-Think maps were properly done by three participants. The notes and lectures given in the classroom were appropriately summarized with suitable i-Think maps type in accordance with the context of the contents. Therefore, the critical thinking skills are said to be properly implied throughout the session. 


\subsection{Document Analysis}

Students' worksheet notes were collected. They were asked to summarise the lesson based on the appropriate i-Think maps that they think suitable to organise the content. By using i-Think maps as active learning tools, critical thinking is encouraged as they have to think independently of the appropriateness of the maps. By having such activities, critical thinking is encouraged. Based on the lecture notes given, the participants summarized the content taught by using appropriate i-Think maps. Below is the analysis of their works.

Table 1. Analysis of students' works

\begin{tabular}{llll}
\hline Participant & $\begin{array}{l}\text { Critical Thinking Level/ Thinking } \\
\text { Process }\end{array}$ & Chosen i-Think map & Task Fulfillment \\
\hline Participant 1: & & & \\
\hline Task 1 & Analysing, cause and effect & Multi-Flow Map & Double-Bubble map \\
Task 2 & $\begin{array}{l}\text { Analysing, comparing and } \\
\text { Creating and classifying }\end{array}$ & Tree Map & $\begin{array}{l}\text { Analyzing cause and effect of language loss } \\
\text { Comparing and contrasting between men and } \\
\text { women language use }\end{array}$ \\
Task 3 & & & Classifying the agents of socialization \\
\hline Participant 2: & Applying, constructing and & Flow Map & Evolutions of culture and society \\
\hline Task 1 & sequencing & Tree Map & Key concepts and definitions of regional and \\
Task 2 & Evaluating and classifying & social dialects \\
Task 3 & Analysing, cause and effect & Multi-Flow Map & Cultural loss and maintenance \\
\hline Participant 3: & & & The types of language change \\
\hline Task 1 & Creating and Classifying & Tree Map & The evolution of culture and society \\
Task 2 & Creating and Classifying & Tree Map & The etymology \\
Task 3 & Analysing and defining in context & Circle map & \\
\hline
\end{tabular}

The findings have proven that when students utilized the i-Think maps, they were able to achieve greater understanding than those who used traditional note-taking methods.

Table 2. Document analysis checklist

Level: 1. weak; 2. moderate; 3 . satisfactory; 4. good; 5. excellent

\begin{tabular}{|c|c|c|c|c|c|c|c|c|c|c|}
\hline \multicolumn{2}{|c|}{ Name: Participant 1} & \multicolumn{4}{|c|}{ Class: 1PISMP TESL } & & \\
\hline & \multicolumn{5}{|c|}{ Initial Student Work } & & & & & Final Student Work \\
\hline Task 1 & 1 & (2) & 3 & 4 & 5 & 1 & 2 & 3 & (4) & 5 \\
\hline Task 2 & 1 & (2) & 3 & 4 & 5 & 1 & 2 & (3) & 4 & 5 \\
\hline Task 3 & 1 & (2) & 3 & 4 & 5 & 1 & 2 & 3 & (4) & 5 \\
\hline \multicolumn{11}{|c|}{ Name: Participant $2 \quad$ Class: 1PISMP TESL } \\
\hline & \multicolumn{5}{|c|}{ Initial Student Work } & \multicolumn{5}{|c|}{ Final Student Work } \\
\hline Task 1 & 1 & 2 & (3) & 4 & 5 & 1 & 2 & 3 & (4) & 5 \\
\hline Task 2 & 1 & (2) & 3 & 4 & 5 & 1 & 2 & (3) & 4 & 5 \\
\hline Task 3 & 1 & (2) & 3 & 4 & 5 & 1 & 2 & 3 & (4) & 5 \\
\hline \multicolumn{11}{|c|}{ Name: Participant $3 \quad$ Class: 1PISMP TESL } \\
\hline & \multicolumn{5}{|c|}{ Initial Student Work } & \multicolumn{5}{|c|}{ Final Student Work } \\
\hline Task 1 & 1 & (2) & 3 & 4 & 5 & 1 & 2 & (3) & 4 & 5 \\
\hline Task 2 & 1 & (2) & 3 & 4 & 5 & 1 & 2 & (3) & 4 & 5 \\
\hline Task 3 & 1 & (2) & 3 & 4 & 5 & 1 & 2 & 3 & (4) & 5 \\
\hline
\end{tabular}

Pre \& post score of the students' works

\begin{tabular}{llllll}
\hline Participants & Pre & & Post & Improvement \\
\hline & Marks (15) & Percentage (\%) & Marks (15) & Percentage (\%) & Percentage (\%) \\
P1 & 6 & 40.0 & 14 & 93.3 & 53.3 \\
P2 & 7 & 46.7 & 14 & 93.3 & 46.6 \\
P3 & 7 & 46.7 & 13 & 86.7 & 40.0 \\
\hline
\end{tabular}




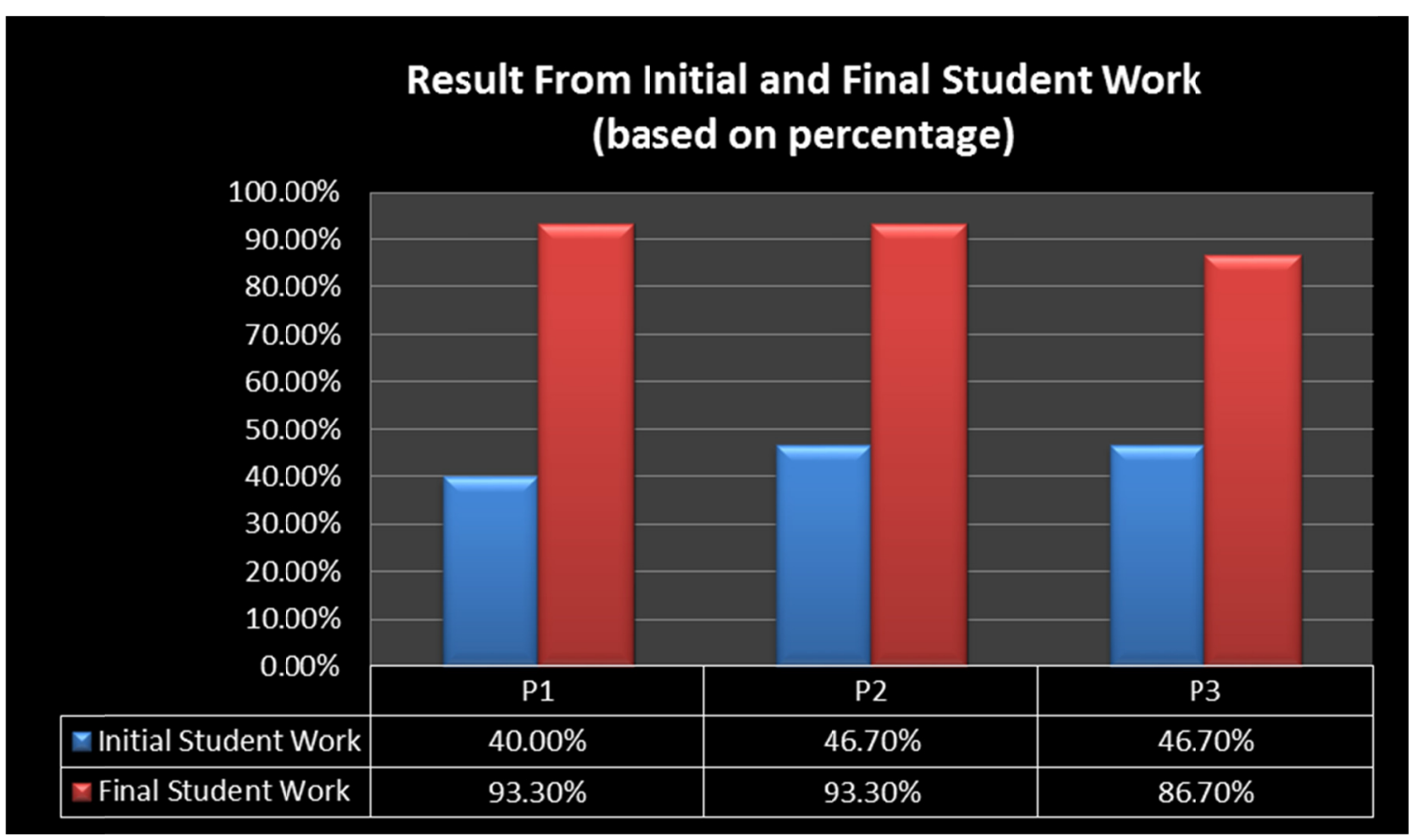

Figure 3. Result of students' work

\subsection{Interview}

In analyzing the interview data, keywords coding for the textual data was used.

Table 3. Data coding

\begin{tabular}{lll}
\hline Participant 1 & Keywords Coding & Interview Excerpt \\
\hline Question 1 & Enjoyable & Yes \\
Question 2 & Express thoughts & It consists of various shapes and types. \\
Question 3 & Develop Thinking & It can help us to analysis issue. \\
\hline Participant 2 & Keywords Coding & Textual Data \\
\hline Question 1 & Enjoyable & Yes, indeed \\
Question 2 & Express thoughts & help us to transfer idea \\
Question 3 & Develop Thinking & It has specific functions so I need to organise information. \\
\hline Participant 3 & Keywords Coding & Textual Data \\
\hline Question 1 & Enjoyable & Of Course \\
Question 2 & Express thoughts & can organise information \\
Question 3 & Develop Thinking & well-organised information will make it easy for me \\
\hline
\end{tabular}

\section{Discussion and Conclusion}

The interview sessions with the three students reveal that they are pleased to deal with activities that promote critical thinking in their classroom learning. The participants were very interested in using i-Think maps because the maps help them to understand and retain the learnt subject better. They claimed i-Think maps as a fun way of learning that helps them to avoid boredom in handling their studies. Thus, it can be said that i-Think maps are the suitable intervention to be used in the classroom as the features help the users (in this case the student teachers) to use active thinking skills to think critically over a particular input. By using i-Think maps, it helps to enlighten educators and teachers to understand the ways to promote critical thinking skills in their teaching and learning process. Therefore, i-Think maps deserve high consideration to be included as one of their frequently used teaching methodologies.

Based on this study, some suggestions are proposed in order to enhance the use of i-Think maps. Firstly, a software or template of the various types of i-Think maps should be developed so it can be accessed easily using computers by the teachers as well as the students. Secondly, for further research, since this study was restricted 
to the teaching of English Language, it is recommended that this study is replicated on other subjects that require critical thinking skills to be applied. Next, in order to ensure greater understanding of i-Think maps and critical thinking, it is recommended for other researchers to conduct more studies in implementing the tools in real classroom settings as it can help in terms of classifying of the right maps to be used in the right level. Other than that, further research should increase the sample size by including a larger number of students from all levels. More intervention plan can be used in using i-Think maps to enhance students' understanding of critical thinking skill embedded in the lesson taught in the classrooms.

\section{References}

Ab Kadir, M. A. (2017). What teacher knowledge matters in effectively developing critical thinkers in the 21 st century curriculum?. Thinking Skills and Creativity, 23(2), 79-90. https://doi.org/10.1016/j.tsc.2016.10.011

Anderson, L. W., Krathwohl, D. R., \& Bloom, B. S. (2001). Taxonomy for learning, teaching, and assessing: A revision of Bloom's taxonomy of educational objectives. Boston, MA: Allyn \& Bacon.

Anh, V. T. K. (2017). Evaluating the implementation of Action Research Course in an in-service teacher training $\begin{array}{lllll}\text { program in Vietnam. Journal of Nusantara Studies, } & \text { 88-97. }\end{array}$ https://doi.org/10.24200/jonus.vol2iss2pp88-97

Bloom B. S. (1956). Taxonomy of educational objectives, Handbook I: The cognitive domain. New York: David McKay Co Inc.

Browne, N. M., \& Freeman, K. (2000). Distinguishing features of critical thinking classrooms. Teaching in Higher Education, 5(3), 301-309. https://doi.org/10.1080/713699143

Camp, E. (2007). Thinking with maps. Philosophical Perspectives, 21(1), 145-182. https://doi.org/10.1111/j.1520-8583.2007.00124.x

Gelder, V. T. (2005). Teaching critical thinking. Some lessons from cognitive science. Journal of College Teaching, 53(1), 41-46. https://doi.org/10.3200/CTCH.53.1.41-48

Hassan, S. R., Rosli, R., \& Zakaria, E. (2016). The use of i-Think map and questioning to promote higher-order thinking skills in Mathematics. Creative Education, 7(1), 1069-1078. https://doi.org/10.4236/ce.2016.77111

Hyerle, D., \& Yeager, C. (2007). Thinking maps: A language for learning. Cary, NC: Thinking Maps, Inc.

Kementerian Pendidikan Malaysia. (2013). Pelan pembangunan pendidikan Malaysia 2013-2025. Putrajaya: Bahagian Pendidikan Guru.

Kemmis, S., \& Mc Taggart, R. (2000). Participatory action research. In N. K. Denzin \& Y. S. Lincoln (Eds.), Handbook of Qualitative Research (567-605). Thousand Oaks, CA: Sage.

Moon, J. (2008). Critical Thinking: An exploration of theory and practice. London: Routledge.

Santiago, H. C. (2011). Visual mapping to enhance learning and critical thinking skills. Optometric Education, 36(3), 125-139.

Savich, C. (2009). Improving critical thinking skills in history. Networks Online Journal, 11(1), 1-12. https://doi.org/10.4148/2470-6353.1106

\section{Copyrights}

Copyright for this article is retained by the author, with first publication rights granted to the journal.

This is an open-access article distributed under the terms and conditions of the Creative Commons Attribution license (http://creativecommons.org/licenses/by/4.0/). 